\title{
Uso de Resistividade, VLF e SP na Caracterização do Modelo Calha Elúvio-Aluvionar de Acumulação de Água Subterrânea em Terrenos Cristalinos: Exemplo da Fazenda Santa Rita/RN
}

Jesimael Avelino da Silva ${ }^{1}$, Walter Eugênio de Medeiros $^{2}$, Emanuel Ferraz Jardim de Sá ${ }^{2}$, Carlos César Nascimento da Silva², Josibel Gomes de Oliveira Júnior ${ }^{* 2}$.

${ }^{1}$ Departamento de Polícia Federal, ${ }^{2}$ UFRN

Copyright 2021, SBGf - Sociedade Brasileira de Geofísica

This paper was prepared for presentation during the $17^{\text {th }}$ International Congress of the Brazilian Geophysical Society held in Rio de Janeiro, Brazil, 16-19 August 2021.

Contents of this paper were reviewed by the Technical Committee of the $17^{\text {th }}$ International Congress of the Brazilian Geophysical Society and do not necessarily represent any position of the SBGf, its officers or members. Electronic reproduction or represent any position of the SBG, its oflcers or members. Elhctron the witen consention storage of any part of this paper for commercial purposes without the written consen of the Brazilian Geophysical Society is prohibited.

\begin{abstract}
The integrated use of geophysical methods allowed to characterize the model of groundwater accumulation in the Santa Rita farm (Santa Cruz/RN). Three VLF profiles, three spontaneous potential profiles (SP) and three apparent resistivity sections were surveyed to investigate the local form of groundwater accumulation. The resistivity sections were obtained with the Schlumberger array and the VLF profiles with surveyed by using the source station GBR (frequency of $16,0 \mathrm{KHz}$ ). The geophysical data show the presence of a relatively wide and thick alluvium and/or regolith, covering the crystalline rocks. On the other hand, no clear indication of relevant fractures is present; that is, the data evidence a structure of groundwater accumulation that cannot be explained satisfactorily by the classic model named "fracture-creek" ("riacho-fenda"). The local groundwater accumulation is better explained by a model where the pore space is associated with the weathering of the crystalline rock along the foliation surfaces. The associated structure of groundwater accumulation is named as alluvium and regolith channel ("calha elúvio-aluvionar").
\end{abstract}

\section{Introdução}

Neste trabalho apresentamos os resultados de um levantamento geofísico realizado com os métodos de eletrorresistividade, potencial espontâneo (SP) e VLF na Fazenda Santa Rita, localizada no Município de Santa Cruz/RN (Silva, 2000). O propósito desses estudos foi caracterizar uma estrutura de acumulação de água em rochas cristalinas, denominado calha elúvio-aluvionar (Silva, 2000).

A área de estudo está situada num domínio litológico de ortognaisses granodioríticos a tonalíticos, por vezes com bandas de anfibolito. Também ocorrem pequenas intrusões de granitos e pegmatitos, na forma de diques e veios. A foliação local está disposta preferencialmente na direção E-W, apresentando mergulhos em torno de $45^{\circ}$ para sul. As fraturas ocorrem dispersas nos afloramentos e apresentam direções NNW (predominante) e NE (Figura 01). Foram perfurados 6 poços, dos quais 2 estão em operação, 2 encontram-se desativados, e 1 poço não produziu. O local possui ainda duas cacimbas, uma das quais escavada num local onde existia um poço (Figura $01)$.

Os poços apresentam profundidade variando de 30 a 50 $\mathrm{m}$, com revestimento na porção inicial até a profundidade de cerca de $4 \mathrm{~m}$, geralmente acompanhando a espessura do aluvião. De acordo com as descrições das fichas de perfuração, o nível estático da água nos poços varia de 5 a $8,4 \mathrm{~m}$ e as entradas de água nos poços estão concentradas no intervalo de 6 a $19 \mathrm{~m}$. Registre-se que os poços foram perfurados em diferentes épocas do ano. A cacimba situada na extremidade leste da área possui aproximadamente $5 \mathrm{~m}$ de profundidade, estando totalmente escavada no aluvião. Uma outra cacimba, na extremidade oeste do trecho investigado do riacho, possui profundidade de $7 \mathrm{~m}$ e nível de água a $5 \mathrm{~m}$.

\section{Métodos}

O levantamento geofísico foi composto por três linhas de medidas (transversais 06, 07 e 08), todas com direção $\mathrm{N}$ $\mathrm{S}$, aproximadamente perpendiculares ao riacho e passando próximas aos poços perfurados (Figura 01). Nestas transversais foram levantadas seções de resistividade aparente, perfis de SP e de VLF.

Os perfis de VLF posicionados sobre as transversais 06, 07 e 08 foram adquiridos com o auxílio da estação GBR (frequência de $16,0 \mathrm{kHz}$ ). Em todos os perfis as medidas foram obtidas a cada $5 \mathrm{~m}$. O filtro linear utilizado foi proposto por Karous \& Hjelt (1983). Adicionalmente, os perfis de VLF são adimensionais como resultado da normalização em relação ao campo primário e são expressos em percentual.

As seções de resistividade aparente foram obtidas com o arranjo Schlumberger, com separação entre as estações de $20 \mathrm{~m}$ e aberturas $A B / 2$ de 2, 5, 10, 20 e $50 \mathrm{~m}$ ). As sondagens elétricas 1 e $2 \mathrm{~A}$, levantadas na transversal 06 , permitiram um conhecimento preliminar das camadas geoelétricas do terreno e serviram para definir as melhores aberturas de eletrodos a serem usadas nas seções de resistividade aparente.

\section{Resultados}

A seção de resistividade aparente da transversal 06 (Figura 02) apresenta, em ambas as bordas, elevações nos valores de resistividade aparente, sendo a elevação 
da borda sul mais proeminente e com maior inclinação entre as estações $80 \mathrm{~m}$ e $100 \mathrm{~m}$. No centro da seção, as linhas de isovalores de resistividade aparente estão subhorizontais. Em dois locais (estações $-110 \mathrm{~m}$ e -40 $\mathrm{m})$, são observados rebaixamentos das linhas de isovalores de resistividade aparente. $\mathrm{Na}$ estação $-110 \mathrm{~m}$ este rebaixamento é detectado desde as menores aberturas de $A B / 2$, indicando que este comportamento é devido basicamente a uma maior espessura da camada areno-argilosa superficial. Por outro lado, na estação -40 $m$, o rebaixamento só é observado nas aberturas de $A B / 2$ $>20 \mathrm{~m}$, sugerindo, neste caso, que o rebaixamento é provocado por uma maior espessura do cristalino fraturado e/ou alterado.

Com base na seção de resistividade aparente e nas sondagens elétricas 1 e $2 A$ (que estão situadas nas estações $-40 \mathrm{~m}$ e $0 \mathrm{~m}$, respectivamente) foi proposta a interpretação ilustrada na Figura 03. Nesta interpretação, os limites sul e norte representam o cristalino subaflorante, sendo que na borda sul o mesmo está bem mais próximo à superfície $(<1,0 \mathrm{~m})$ e possui um maior gradiente topográfico. A camada areno-argilosa apresenta variações laterais de resistividade; no entanto, sua espessura varia pouco na porção central da estrutura. O cristalino fraturado e/ou alterado apresenta uma ampla variação de espessura ao longo da estrutura, sendo que na estação $-40 \mathrm{~m}$ ele atinge sua maior espessura, em torno de $13 \mathrm{~m}$.

$\mathrm{O}$ perfil de VLF levantado nessa transversal (Figura 04) mostra que, na porção central da aluvião, ocorrem apenas variações pequenas e irregulares nas curvas de densidade de corrente. Nas bordas norte e sul da estrutura, são observadas anomalias na densidade de corrente, certamente associadas ao contraste lateral de condutividade entre o aluvião e o cristalino.

O perfil de SP da transversal 06 (Figura 05) mostra duas anomalias negativas, uma na estação $-40 \mathrm{~m}$ e outra na estação $-140 \mathrm{~m}$. Estas anomalias indicam locais com provável movimentação de água. Na estação -40 m está localizado um poço. Parte desta anomalia poderia ser explicada pelo próprio bombeamento do poço, que estava em funcionamento por ocasião da aquisição. A anomalia de maior largura, observada entre as estações $60 \mathrm{~m}$ e $0 \mathrm{~m}$, pode ser interpretada como sendo causada por uma barreira impermeável (Schiavone \& Quarto, 1984), que certamente é o ressalto do embasamento cristalino (comparar com a seção de resistividade aparente).

As seções de resistividade aparente das transversais 07 e 08 mostram aspectos similares à seção da transversal 06. A transversal 07 (Figura 06) apresenta suas bordas norte e sul caracterizadas por altos valores de resistividade aparente; no centro, as linhas de isovalores de resistividade aparente estão horizontalizadas. Nas estações $40 \mathrm{~m}$ e $0 \mathrm{~m}$ ocorrem rebaixamentos bruscos das linhas de isovalores de resistividade aparente desde os menores valores de $A B / 2$, certamente provocados por variações de espessura da camada superficial mais argilosa.

$O$ perfil de VLF da transversal 07 possui uma configuração similar ao anterior (transversal 06) e mostra dois picos significativos de densidade de corrente (Figura 07). O maior situa-se em torno da estação $120 \mathrm{~m}$, enquanto o menor encontra-se na outra extremidade do perfil, próximo à estação - $60 \mathrm{~m}$. Nas demais estações, situadas no trecho em que a espessura de aluvião é maior, as curvas de densidade de corrente não apresentam elevações importantes, indicando ausência de estruturas significativas (fraturas) na porção central do perfil; as elevações nas bordas do perfil são resultantes do contraste lateral entre o cristalino subaflorante e os sedimentos argilo-arenosos.

O perfil de SP da transversal 07 mostra quase todos os valores estão variando no intervalo de 0 a $20 \mathrm{mV}$ (Figura 08). Os mínimos deste perfil situam-se nas estações 20 $\mathrm{m}$ e - $60 \mathrm{~m}$. Em particular, a anomalia da estação $20 \mathrm{~m}$, a exemplo daquela citada na transversal anterior, também poderia refletir a influência do bombeamento do poço. Por outro lado, o pico na estação - $80 \mathrm{~m}$ poderia ser interpretado como uma barreira impermeável correspondente à borda da rocha cristalina sã.

A seção de resistividade aparente da transversal 08 (Figura 09) vem confirmar o comportamento mostrado nas demais seções. Na borda sul (estações $80 \mathrm{~m}$ e $60 \mathrm{~m}$ ) ocorrem valores elevados de resistividade aparente devido ao afloramento do cristalino. Nas demais estações, as linhas de isovalores de resistividade aparente estão horizontalizadas e os valores são pequenos. Cabe ressaltar que esta transversal corta o local onde existe um pequeno açude, tendo assim a presença de argila saturada em água, o que explica os menores valores de resistividade aparente observados.

O perfil de VLF da transversal 08 (Figura 10) mostra uma pequena anomalia de densidade de corrente em torno da estação $60 \mathrm{~m}$, que é interpretado como sendo provocado pelo contraste de condutividade na interface lateral entre o cristalino e os sedimentos.

O perfil de SP da transversal 08 (Figura 11) é caracterizado por apresentar uma anomalia de valor negativo para a estação $60 \mathrm{~m}$. Segundo observações de campo e os dados da seção de resistividade aparente e VLF, esta estação localiza-se no limite entre a barreira do cristalino e os sedimentos argilo-arenosos. A análise integrada dos dados de VLF, SP e resistividade não revela a presença de anomalias que possam ser associadas à presença de fraturas expressivas, de modo que a acumulação de água deve ocorrer predominantemente no espaço poroso criado pelo intemperismo, que foi desenvolvido aproveitando os planos de foliação da rocha, ao contrário do que ocorre no modelo riacho-fenda (Costa 1997).

\section{Conclusões}

Este trabalho apresentou os resultados de um levantamento geofísico com os métodos da eletrorresistividade, SP e VLF para caracterizar uma estrutura diferente de acumulação de água em rochas cristalinas na Fazenda Santa Rita/RN.

A estrutura, que foi denominada de calha elúvioaluvionar, é dominantemente controlada pelo intemperismo ao longo dos planos de foliação da rocha, conjugado ao contexto geomorfológico local. A interpretação dos dados geofísicos, em conjunto com dados estruturais de campo, permitiu identificar características importantes do modelo calha elúvioaluvionar: (a) Ausência de fraturas expressivas controlando a estrutura; (b) As anomalias de VLF no centro da estrutura não apresentaram continuidade de 
um perfil a outro, quando se comparam vários perfis; (c) Os dados de eletro-resistividade (seções de resistividade aparente), definiram muito bem as bordas da estrutura com alta resistividade e o centro da estrutura com resistividade menor.

\section{Agradecimentos}

Os autores agradecem as discussões e participação de Ana Catarina Fernandes Coriolano e Elmo Marinho de Figueiredo (ex-CDM/RN) nos trabalhos de campo. Este trabalho foi financiado pelo programa PADCT3, junto com bolsas do CNPq e CAPES, concedida aos autores.

\section{Referências}

COSTA, W.D. 1997. Hidrogeologia de meios anisotrópicos. In: Hidrogeologia - Conceitos e Aplicações. CPRM. Fortaleza. p. 133-184.

KAROUS, M \& HJELT, S.E. 1983. Linear filtering of VLF dip-angle measurements. Geophysical Prospecting, 31. 782-794.

SCHIAVONE, D. \& QUARTO, R. 1984. Self-potential prospecting in the study of water movements. Geoexploration, 37: 47-58.

SILVA, J.A. 2000. Estruturas de acumulação de água subterrânea em rochas cristalinas: estudo geofísico e geológico de casos no Estado do Rio Grande do Norte. Dissertação de Mestrado, PPGG/UFRN.

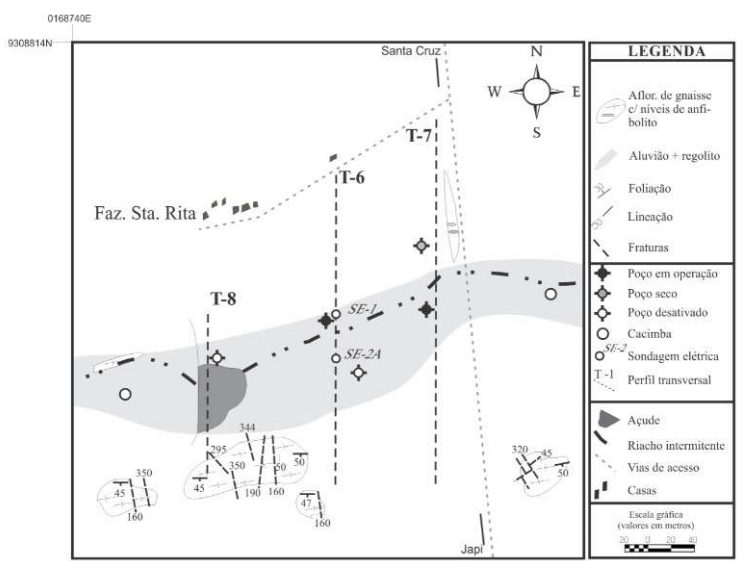

Figura 01 - Mapa de situação mostrando a disposição dos elementos geológicos e geográficos, bem como as linhas e locais das medidas geofísicas.

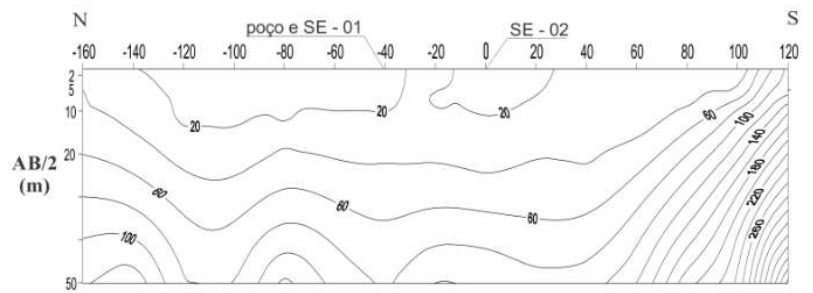

Figura 02 - Seção de resistividade aparente na transversal 06. Valores em Ohm.m Arranjo Schlumberger.

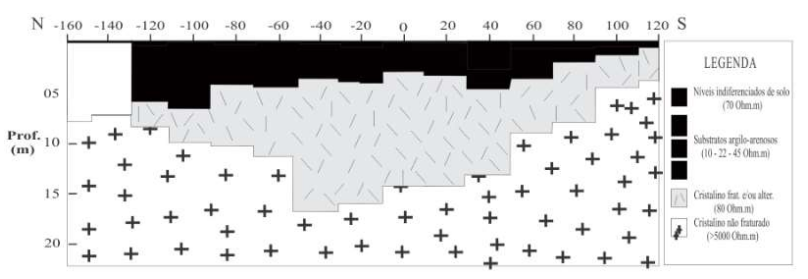

Figura 03 -Modelo geoelétrico para seção 06.

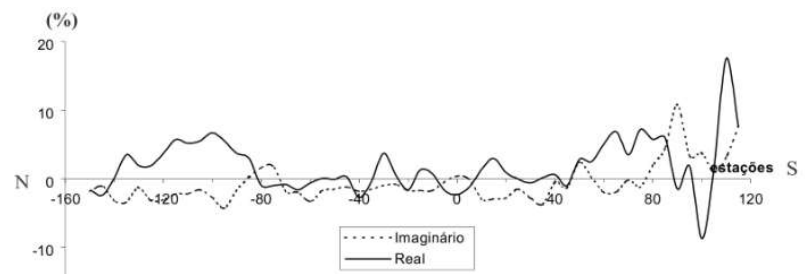

Figura 04 - Perfil de VLF da transversal 06.

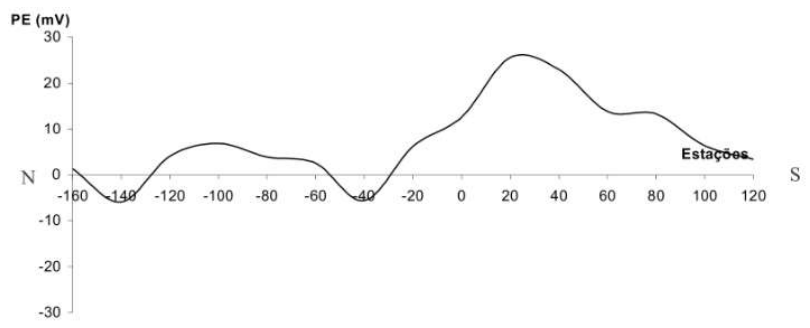

Figura 05 - Perfil de potencial espontâneo (SP) da transversal 06.

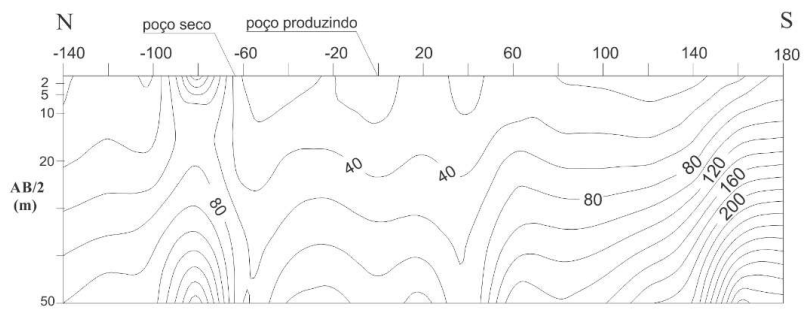

Figura 06 - Seção de resistividade aparente na transversal 07 . Valores em Ohm.m Arranjo Schlumberger. 


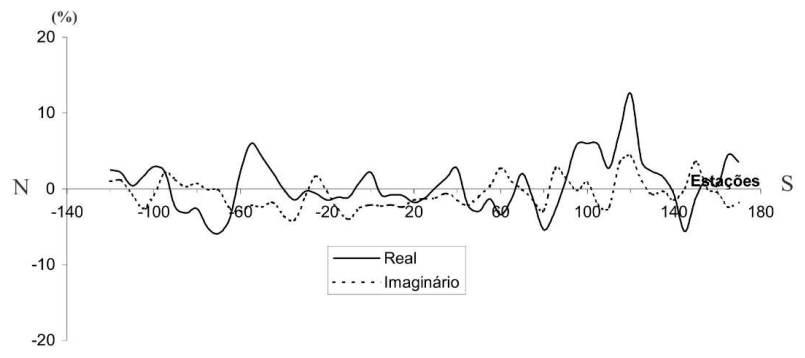

Figura 07 - Perfil de VLF da transversal 07.

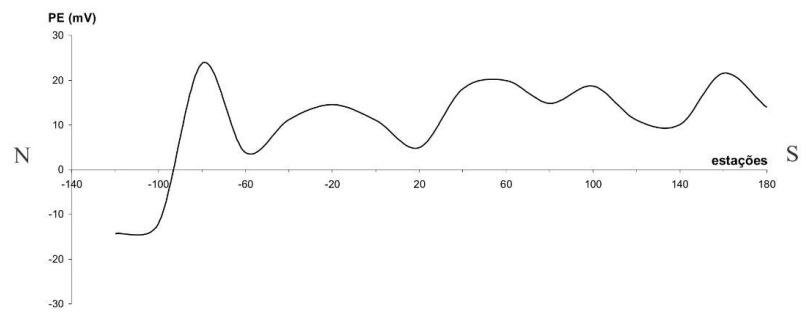

Figura 08 - Perfil de potencial espontâneo (SP) da transversal 07.

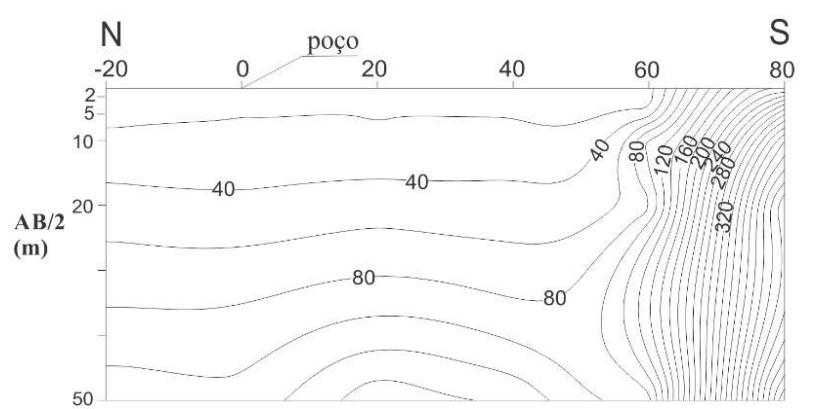

Figura 09 - Seção de resistividade aparente na transversal 08. Valores em Ohm.m Arranjo Schlumberger.

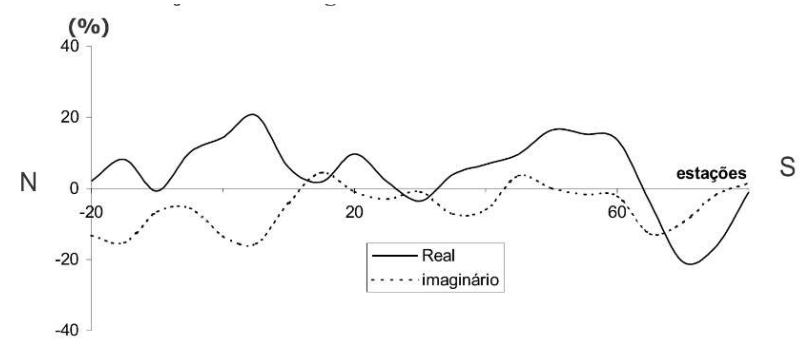

Figura 10 - Perfil de VLF da transversal 08.

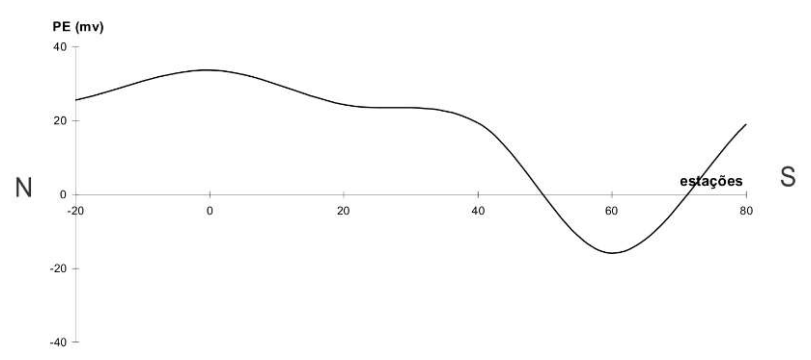

Figura 11 - Perfil de potencial espontâneo (SP) da transversal 08. 